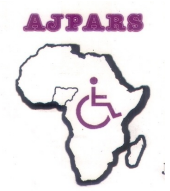

\title{
Gender and Postural Differences in Cardiovascular Response to Hand Grip Exercise Among Elderly Normotensives
}

\author{
Kodzo, K.K. ${ }^{1}$, Mohammed, J. ${ }^{2}$, Kodzo, P. ${ }^{1}$ \\ ${ }^{1}$ Department of Physiotherapy, Aminu Kano Teaching Hospital, Kano \\ ${ }^{2}$ Department of Physiotherapy, Bayero University, Kano \\ Correspondence: \\ Mohammed, J・jibrilphysio84@yahoo.com
}

\begin{abstract}
SUMMARY
Cardiovascular ( $\mathrm{CV}$ ) response to isometric exercise among the elderly is still widely underreported. This study was carried out to investigate $\mathrm{CV}$ response to hand grip (HG) exercise among elderly individuals, in seated and supine positions.

Thirty (15 males and 15 females) elderly (60 years and above), apparently healthy normotensive (<140/90 $\mathbf{m} \mathbf{m} \mathrm{H}$ ) individuals were recruited to participate in this study. The mean ages of male and female participants were $72 \pm 8.8$ years and $68.5 \pm 9$ years respectively. Their heights and weights were measured using standard procedures. All the participants performed HG exercise using a hydraulic dynamometer at 40 per cent of maximal voluntary contraction (MVC) until failure. Their heart rates, as well as systolic and diastolic blood pressures were measured pre-test and immediately after failure (post-test) with an electronic sphygmomanometer. The multivariate analysis of covariance (MANCOVA) was used to compare the pre- and post-exercise CV parameters of the participants in seated and supine positions.

The results of the study revealed that the male and female participants were similar in age $(p=0.315)$, height $(p=0.174)$ and weight $(p=0.314)$ as well as in their baseline CV variables $(p>0.05)$. The HG exercise caused a significant rise in both systolic and diastolic blood pressure in both seated and supine positions post-exercise $(p<0.05)$. However, heart rate did not show any significant increase $(p=0.063)$. The results also showed no significant gender and postural difference (seated and supine) in all CV responses to hand grip exercise ( $p>0.05)$. It was concluded that gender and posture (seated and supine position) do not affect heart rate, or systolic and diastolic blood pressure response to $\mathrm{HG}$ exercise among elderly normotensives.
\end{abstract}

KEYWORDS: hand grip exercise, elderly normotensive, cardiovascular responses, seated and supine position

\section{INTRODUCTION}

Hand grip (HG) exercise is a form of isometric exercise that has been widely researched in various studies and clinical areas using the standardized protocols (Ohler et al, 2013; Hamza, Wabha \& Megahi 2013; Carnivel, Wyatt \& Baker, 2012; Yasuo et al, 2005). Grip strength testing is used as a predictor of physical functioning, for assessment of upper limb impairment, evaluation of nutritional status, injury prevention and rehabilitation, and to monitor progression of muscle strength (Hamza, Wabha \& Megahi 2013; De et al
2011). Hand grip exercise is also reported to enhance performance of individuals (Carnivel Wyatt \& Baker, 2012).

Past studies investigating isometric hand grip exercises featured the use of various body positions (Richards, 1997), upper limb joint placements (Yasuo et al, 2005), across gender (Dopsaj et al, 2007; Mbada et al, 2007) and among different age groups (Bakke et al 2007) with a view to providing normative data or rehabilitation. Although, isometric exercises such as hand grip testing have been 
reported to cause a characteristic increase in blood pressure and other cardiovascular parameters (Bakke et al, 2007), the cardiovascular response to isometric exercise largely depends on factors such as volume of muscle mass involved, duration, intensity, number of contractions and total workload (Ohler et al, 2013).

With ageing, the vascular wall changes, becoming less elastic and stiffer, which may place the elderly at risk of undesirable cardiovascular responses (Cheitlin, 2003). It is also a known fact that hand grip exercise has a pressor effect on the cardiovascular system, and can therefore cause increases in blood pressure that can be dangerous to elderly individuals (Bakke et al, 2007; Glover, 2008). Bakke et al (2007) revealed that cardiovascular response to hand grip exercise has been widely reported by previous works. They further stated that most of the findings of these studies are contradictory.

A few studies examining the practical posture for hand grip have recommended the use of standing, sitting and supine lying positions during testing (De et al, 2011; Hillman et al 2005; Richards, 1997). The elbow as well as other upper limb joint placement also varies from study to study. Ng and Fan (2001) stated that most of the past studies have concentrated on the effect of different upper limb positions with little focus on body position or posture. Hillman et al (2005) stated that the optimal position of the body during hand grip measurement is still open to debate.

Generally, there is insufficient data on factors affecting cardiovascular response to hand grip testing exercise among elderly normotensives. This study was therefore designed to investigate gender differences in cardiovascular response to upper extremity isometric exercise in the seated and supine positions among elderly normotensives, with a view to determining the optimal position for the exercises in this group.

\section{METHODOLOGY}

\section{Research Design and Subjects}

The study was conducted using a pretest-post-test quasiexperimental research design. The population of the study comprised apparently healthy normotensive (with blood pressure $<140 / 90 \mathrm{mmHg}$ ) elderly (60 years and above) individuals from the Old People's Home, Shahuci in Kano State. Thirty individuals were recruited (15 males and 15 females) to participate in the study using the purposive sampling technique.

\section{Procedure}

Ethical clearance was obtained from the Ethics Committee of the Kano State Emergency Relief and Rehabilitation Agency. The participants were recruited and their consent sought after the procedure and benefits of the study had been explained to them. The participants were also given the choice to withdraw from the study at any point if they so desired. Their demographic characteristics, including age, weight, and height, were assessed and recorded prior to the commencement of hand grip testing.

The hand grip exercise was performed using a hydraulic isometric hand grip apparatus (PhysioMed; England). For each participant, the handle of the dynamometer was adjusted to a comfortable grip with the base of the dynamometer resting on the first metacarpal (heel of palm), while the handle rested on the middle of the four fingers (Lemmink et al, 2001). All tests were done using the dominant hand of each participant.

Prior the actual hand grip exercise, the maximal voluntary contractions (MVCs) value was obtained for each participant in both seated and supine positions. Each participant was asked to squeeze the handle of the dynamometer with maximum possible effort for 5 seconds with the shoulder fully adducted, elbow in 90 degrees of flexion and the wrist joint in neutral position. A participant's single best voluntary contraction of three trials was then recorded as the individual's MVC. The resting period between trials was approximately 30 seconds (Handgrip strength test, 2011). Throughout the trials, the participants were instructed to refrain from muscular contractions other than those involved in the hand grip contraction. The supine and seated test for each participant was done three days after MVC measurement.

Supine lying test: The supine tests were done with the subject lying on a couch, the reference upper limb (dominant arm) shoulder was fully adducted, the elbow in 90 degrees flexion, the wrist joint in neutral position with the hand firmly gripping the handle of the dynamometer during the test. Each participant was instructed to maintain an intensity that is approximately 40 per cent of his/her MVC, and this was done by monitoring the gauge on the dynamometer signaling when effort had to be increased or decreased. The participants maintained this intensity until failure (Melrose, 2005) i.e., when 40 per cent of MVC could no longer be maintained within 10 per cent of the participant's predetermined value (Melrose, 2005). 
Gender and Postural Differences in Cardiovascular Response to Hand Grip Exercises in Elderly Normotensive

Seated test: The seated tests were done in high sitting position (on a stool/stand) with the upper body in an erect posture, the reference upper limb (dominant arm) shoulder fully adducted, elbow in 90 degrees flexion, the wrist joint in neutral position with the hand firmly gripping the handle of the dynamometer during the test. Each participant was then instructed to maintain an intensity that is approximately 40 per cent of his/her MVC by monitoring the gauge on the dynamometer signaling when effort had to be increased or decreased. The participant maintained this intensity until failure (Melrose, 2005), i.e. when 40 per cent of MVC could no longer be maintained within 10 per cent of the participant's predetermined value (Melrose, 2005).

During the hand grip exercise in both seated and lying positions, the participants' blood pressures and heart rate measurements were measured with a blood pressure monitor (Health Sense model BP-103, China) before the hand grip testing and immediately after failure. Thereafter, the participants were asked to rest for 10 minutes before discharge (Mbada et al, 2007).

Descriptive statistics of mean and standard deviation were used to summarize the age, height and weight characteristics of the participants based on gender. Independent t-test was used to compare the male and female participants' physical characteristics. The paired student ttest was used to determine the difference in cardiovascular responses pre- and post-exercise. Gender and postural differences following hand grip exercise was determined using the multivariate analysis of covariance (MANCOVA). Statistical significance was set at $\mathrm{p}<0.05$. All data analysis was done using the Statistical Package for the Social Sciences (SPSS) version 16.0.

\section{RESULTS}

Male and female participants were found to be similar in age $(p>0.315)$, height $(p>0.174)$ and weight $(p>0.314)$ as seen in table 1 . There was no significant $(\mathrm{P}>0.05)$ gender difference in the pre- and post-exercise cardiovascular parameters of the participants. The results of the study also revealed that the hand grip exercise in both seated and supine positions caused a significant rise in both blood pressure variables (SBP and DBP) $(\mathrm{P}<0.05)$. However, heart rate response did not show any significant increase $(\mathrm{P}>0.05)$ following isometric exercise as demonstrated in table 2 .
Table 1. Demographic variables of the participants

\begin{tabular}{llll}
\hline Variables & $\begin{array}{l}\text { Male } \\
\text { Mean } \pm \mathrm{SD} \\
(\mathrm{n}=15)\end{array}$ & $\begin{array}{l}\text { Female } \\
\text { Mean } \pm \mathrm{SD} \\
(\mathrm{n}=15)\end{array}$ & $\mathrm{p}$ \\
\hline Age & $72.44 \pm 8.80$ & $68.46 \pm 8.99$ & 0.315 \\
Height & $1.60 \pm 0.08$ & $1.55 \pm 0.06$ & 0.174 \\
Weight & $50.11 \pm 7.93$ & $44.96 \pm 13.36$ & 0.314 \\
\hline
\end{tabular}

Level of significance $(\mathrm{p}<0.05)$

Table 2. Paired t-test for comparison of the pre- and post-exercise cardiovascular parameters among all the subjects.

\begin{tabular}{lllll}
\hline Variables & $\begin{array}{l}\text { Pre-ex } \\
\text { Mean } \pm \mathrm{SD} \\
(\mathrm{n}=30)\end{array}$ & $\begin{array}{l}\text { Post-ex } \\
\text { Mean } \pm \mathrm{SD} \\
(\mathrm{n}=30)\end{array}$ & $\mathrm{T}$ & $\mathrm{p}$ \\
\hline HR & $80.16 \pm 16.30$ & $81.82 \pm 16.48$ & 1.906 & 0.063 \\
SBP & $120.18 \pm 12.78$ & $125.52 \pm 14.81$ & 5.841 & $0.000^{*}$ \\
DBP & $74.27 \pm 11.08$ & $77.41 \pm 11.17$ & 5.987 & $0.000^{*}$ \\
\hline
\end{tabular}

$\mathrm{HR}=$ Heart Rate; $\mathrm{SBP}=$ Systolic Blood Pressure $\mathrm{DBP}=$ Diastolic Blood Pressure;

*Significant at $\mathrm{p}=0.05$

The findings of the study further revealed that there was no significant gender difference $(P>0.05)$ in the cardiovascular parameters of the participants following hand grip exercise in both seated and supine positions (table 3). Lastly, table 4 presents the results of the cardiovascular responses to hand grip exercise of the participants in the seated and supine positions and shows that there was no significant difference in $\mathrm{CV}$ response between the two.

Table 3. MANCOVA summary of gender differences in post-exercise cardiovascular responses to isometric exercises

\begin{tabular}{lllll}
\hline & $\begin{array}{l}\text { Male } \\
\text { Vean } \pm \mathrm{SE}\end{array}$ & $\begin{array}{l}\text { Female } \\
\text { Mean } \pm \mathrm{SE} \\
(\mathrm{n}=15)\end{array}$ & $\mathrm{F}$ & Prob. \\
\hline Seated HR & $88.59 \pm 3.15$ & $85.82 \pm 2.42$ & 0.344 & 0.567 \\
Supine HR & $73.59 \pm 2.27$ & $78.82 \pm 1.74$ & 2.363 & 0.147 \\
Seated SBP & $127.21 \pm 2.51$ & $131.09 \pm 1.92$ & 1.066 & 0.319 \\
Supine SBP & $122.74 \pm 2.88$ & $126.77 \pm 2.21$ & 0.825 & 0.379 \\
Seated DBP & $77.16 \pm 1.58$ & $80.97 \pm 1.21$ & 2.580 & 0.131 \\
Supine DBP & $77.55 \pm 1.39$ & $73.93 \pm 1.07$ & 2.996 & 0.105 \\
\hline
\end{tabular}

$\mathrm{HR}=$ Heart Rate; SBP $=$ Systolic Blood Pressure DBP $=$ Diastolic Blood Pressure 
Table 4. MANCOVA summary of postural differences in cardiovascular responses to isometric exercises among all the subjects

\begin{tabular}{lllll}
\hline Variables & $\begin{array}{l}\text { Seated } \\
\text { Mean } \pm \mathrm{SE} \\
(\mathrm{n}=30)\end{array}$ & $\begin{array}{l}\text { Supine } \\
\text { Mean } \pm \mathrm{SE} \\
(\mathrm{n}=30)\end{array}$ & $\mathrm{F}$ & $\mathrm{P}$. \\
\hline HR & $82.72 \pm 1.20$ & $80.92 \pm 1.20$ & 1.075 & 0.306 \\
SBP & $120 \pm 1.29$ & $119 \pm 1.29$ & 2.192 & 0.147 \\
DBP & $78.02 \pm 0.77$ & $76.80 \pm 0.77$ & 1.179 & 0.284 \\
\hline
\end{tabular}

$\mathrm{SE}=$ Standard Error; $\mathrm{n}=$ number of subjects; HR $=$ Heart Rate; $\mathrm{SBP}=$ Systolic Blood Pressure; DBP $=$ Diastolic Blood Pressure; Prob.= probability; $\mathrm{F}_{1,39}=4.08$

Level of significance $(\mathrm{P}<0.05)$

\section{DISCUSSION}

This study was designed to investigate gender and postural differences in cardiovascular response to hand grip exercise among elderly normotensive individuals from the Old People's Home, Shahuci, Kano State. The male and female participants were comparable in age, height and weight as well as in the maximum voluntary contraction for both seated and supine positions.

The hand grip exercise produced significant increase in systolic and diastolic blood pressure in all participants. This is in line with the results of past studies on CV response to isometric exercises (Bakke et al, 2007; Ohler et al, 2013; Mbada et al, 2007; Melrose, 2005), and the reason may be due to the stressor effect of isometric exercise such as hand grip on the cardiovascular system. The pre- and postexercise heart rate response to the hand grip exercise in this study was however not significantly different. This finding was in contrast to reports from studies carried out among young individuals (Carnivel Wyatt \& Baker, 2012).The reason for this may be the fact that left ventricular contractility is reduced in older adults during maximal exercise compared with young adults (Fleg et al, 1995), and studies have reported an age-related decline in heart rate response to exercise (Jones et al, 1996).

The seated position in this study resulted in higher HR and BPs at baseline and post-exercise when compared to the lying position. This finding is also supported by the works of Mbada (2007) and Sullivan (2007). This can be attributed to the variation in the effect of gravity on the cardiovascular system, as stated by Sembulingam and Sembulingam, (2006) that the seated or upright position is characterized by pooling of blood in the distal areas of the body, especially the lower limbs, which results in a decrease in cardiac output and thus stimulating the heart to increase rate so as to compensate for this decline as against the lying position were the influence of gravity is minimal.

Posture did not have any significant effect on the cardiovascular responses to the isometric hand grip exercise in this study, which is contrary to the findings of some past studies (Melrose, 2005; Sagiv et al, 1992). This may be attributed to the fact that most studies in hand grip testing were carried out in young and middle-aged people.

Results from this study also showed that there was no significant gender difference in the cardiovascular responses to isometric hand grip exercise. This may be explained by the works of Sullivan (2007), who reported that in the elderly (about age 70 years), the cardiovascular system and rates of cardiovascular disease and hypertension are similar in men and women. This may explain the absence of gender difference found in this study at both baseline and postexercise, and the similarities of the subjects. It was concluded that there are no significant gender and postural differences in cardiovascular response to hand grip testing exercise among elderly normotensives.

It was thus recommended that irrespective of gender, the sitting or lying position can be used for hand grip exercise among elderly normotensives.

\section{ACKNOWLEDGEMENT}

The authors wish to thank the participants, the Kano State Emergency Relief and Rehabilitation Agency and the management and staff of the Old People's Home, Shahuci, Kano State for their invaluable cooperation during the process of this study.

\section{References}

Bakke, E.F., Hisdal, J., Kroese, A.J., Jorgensen, J. and Stranden, E. 2007. Blood pressure response to isometric exercise in patients with pheriperal atherosclerotic disease. Clinical Physiology Functional Imaging 27: 109.

Carnivel, R.G., Wyatt, F.B. and Baker, J.S 2012. The cardiovascular responses to hand grip vs relaxed hand grip in sustained cycling efforts. Journal of Strength Conditioning Research 26 (11): 3101

Cheitlin, M.D. 2003. Cardiovascular physiology changes with ageing. American Journal of Geriatric Cardiology 12: 9-13.

De, S., Sengupta, P., Maity P., Pal, A. and Dhara P.C. 2011. Effect of Body posture on hand grip strength in adult Bengalee population. Journal of Exercise Science and Physiotherapy 7(2): 78-84. 
Gender and Postural Differences in Cardiovascular Response to Hand Grip Exercises in Elderly Normotensive

Dopsaj M., Koropanovski, N., Vuckovic, G., Blagojevic, M., Marinkovic, B. and Milijus, D. 2007. Maximal isometric hand grip force in well-trained university students in Serbia descriptive, functional and sexual dimorphic model. Serbia Journal of Sports Science 1(4): 138-139.

Fleg, J.L., O'Connor, F., Gerstenblith, G., Becker, L.C., Clulow, J., Schulman, S.P. and Lakatta, E.G. 1995. Impact of age on the cardiovascular response to dynamic upright exercise in healthy men and women. Journal of Applied Physiology 78: 890-900.

Glover, M. 2008. Senior safety tips for isometric exercise routines. Retrieved April 8, $2011, \quad$ from http://www.associatedcontent.com

Hamza, S.A., Wahba, H.M.F., Hegazy, M.M. 2013. Assessment of handgrip strength variables in a population of Egyptian elderly. Middle East Journal of Age and Ageing 10(3): 20.

Handgrip strength test. 2011. Retrieved April 14, 2011, from http://www.topendsports.com/ testing /tests/handgrip

Hillman, T.E., Nunes, Q.M., Hornby, S.T., Stanga, Z., Neal, K.R., Rowlands, B.J., Allisson, S.P. and Lobo, D.N. 2005. A practical posture for hand grip dynamometry in the clinical setting. Clinical Nutrition 24(2): 224-8.

Jones, P., Spraul, M., Matt, K., Seals, D., Skinner, J. and Ravussin, E. 1996. Gender does not influence sympathetic neural reactivity to stress in healthy humans. American Journal of Physiology 270: H350-H357.

Lemmink, K.A., Han, K., DeGreef, M.H., Rispens, P. and Stevens, M. 2001. Reliability of the groningen fitness test for the elderly. Journal of Aging and Physical Activity 9: 194-212.

Mbada, C.E., Akinwande, O.A., Babalola, J.F., Seyi-Adeyemo, O.R. and Odejide A.S. 2007. Gender difference in cardiovascular response to upper extremities isometric exercises in normotensive subjects. Nigerian Journal of Medical Rehabilitation 12(20): 30-34.

Melrose, D.R. 2005. Gender differences in cardiovascular responses to isometric exercise in the seated and supine positions. Journal of Exercise Physiology Online 8(4): 29-35.

$\mathrm{Ng}$, G.Y.F. and Fan, A.C.C. 2001. Does elbow position affect strength and reproducibility of power grip measurements? Physiotherapy 87(2): 68-70.

Ohler, R.R.V., Bocalini, D.S., Bacurau, R.F., et al. 2013. Isometric hand grip does not elicit cardiovascular overload or post exercise hypotension in hypertensive older women. Clinical Intervention Aging 8: 649-655.

Richards, L.G. 1997. Posture effects on grip strength. Archives of Physical Medicine Rehabilitation 78(10): 1154.

Sagiv, M., Rotstein, A., Watkins, J., Climor, L. and Ben-Sira, D. 1992.. Effect of body position on the afterload response during sustained exercise. Journal of Sports Medicine and Physical Fitness 32: 170-174.

Sembulingam, K. and Sembulingam, P. 2006. Essentials of Medical Physiology ( $4^{\text {th }}$ ed.. India, New Delhi: Jaypee Brothers Medical Publishers Ltd.

Sullivan, J.C. 2007. Medical College of Georgia: Cause of gender differences in blood pressure, kidney damage under study. Science Daily. Retrieved November 15, 2011, from http://www.sciencedaily.com/releases/

Yasuo, G., Daisaku, T., Nriyuki, M., Jun'ya, S., Toshiko, O., Mashiko, M., Yoshiyuki, M. 2005. Relationship between grip strength and surgical results in rotator cuff tears. Shoulder Joint 29(3): 559-562. 